\title{
Dose-Dependent Reduction of Tissue Loss and Functional Impairment after Spinal Cord Trauma with the AMPA/Kainate Antagonist NBQX
}

\author{
Jean R. Wrathall, David Choiniere, and Yang Dong Teng \\ Neurobiology Division, Department of Cell Biology, Georgetown University, Washington, D.C. 20007
}

Initial studies on the role of glutamate receptors in traumatic spinal cord injury (SCI) implicated the NMDA subclass of ionotropic glutamate receptors in contributing to functional deficits. Recently we obtained evidence suggesting that nonNMDA ionotropic receptors may participate in producing a portion of the behavioral impairment after $\mathrm{SCl}$. To test this hypothesis we have conducted a dose-response experiment, focally injecting 2,3-dihydroxy-6-nitro-7-sulfamoylbenzo(f)quinoxaline (NBQX; $1.5,5$, or $15 \mathrm{nmol}$ ), a highly selective antagonist of $\alpha$-amino-3-hydroxy-5-methyl-4-isoxazole propionic acid (AMPA)/kainate receptors, or vehicle alone, into the injury site beginning at $15 \mathrm{~min}$ after a standardized contusive SCl. Behavioral tests of hindlimb reflex and coordinated sensorimotor function were performed $1 \mathrm{~d}$ after injury and weekly thereafter. At 4 weeks, spinal cord tissue was examined using quantitative histopathological and immunocytochemical techniques. We found a dose-dependent reduction in tissue loss at the thoracic injury site, with greater residual amounts of both gray matter and myelinated white matter. The maximum dose (15 nmol) significantly reduced the average length of the lesions and doubled the area of residual white matter at the epicenter. Serotonin immunoreactivity caudal to the lesion, used as a marker for descending motor control axons, was also increased in a dose-related manner and nearly tripled with the highest dose of NBQX as compared to controls. Most importantly, the reduced tissue loss in NBOX-treated groups was correlated with reduced functional deficits. There was a dose-dependent enhancement of speed and degree of recovery of both reflex and coordinated hindlimb motor activity, and reduction in the time required for establishing a reflex bladder. The long-term functional deficits at 4 weeks after $\mathrm{SCl}$ were reduced in a dose-related manner. Further, regression analyses demonstrated a significant correlation between the increase in amount of residual tissue and improvement in hindlimb function. Our results suggest that in this type of incomplete contusive $\mathrm{SCl}$, a large and functionally important proportion of the tissue loss appears to be

\footnotetext{
Received Dec. 10, 1993; revised Apr. 4, 1994; accepted Apr. 27, 1994.

We thank Novo Nordisk A/S (Malov, Denmark) for the gift of NBQX, and Dr. Dianne Mundt for assistance in some of the statistical analyses of the data. The work was supported by the National Institutes of Health, PO1-NS28130.

Correspondence should be addressed to Dr. Jean R. Wrathall, Neurobiology Division, Department of Cell Biology, Georgetown University, 3900 Reservoir Road, N.W., Washington, DC 20007.

Copyright (C) 1994 Society for Neuroscience $0270-6474 / 94 / 146598-10 \$ 05.00 / 0$
}

due to secondary injury mediated by local AMPA/kainate receptors.

IKey words: rat, spinal cord injury, NBQX, ionotropic glutamate receptors, non-NMDA receptors, AMPA, kainate, motor function, histopathology, serotonin]

The slow development of histopathological changes and lengthy period required for stabilization of the lesions (Allen, 1914; Ducker et al., 1971; Ballentine, 1978a,b; Bresnahan, 1978; Noble and Wrathall, 1989a) have long suggested that secondary injury processes exacerbate the effects of the initial mechanical insult after traumatic SCI. Strong evidence for the importance of secondary injury comes from the demonstration that various postinjury treatments can reduce neurological impairment resulting from a standardized experimental injury (e.g., Allen et al., 1911; Hansebout et al., 1975; Faden et al., 1990). One postinjury treatment, high doses of the steroid methylprednisolone, has now been found effective in large-scale clinical trials with human spinal cord injury patients (Bracken et al., 1990). However, many physiological and biochemical alterations after SCI have been described that may be involved in secondary injury processes (Blight, 1991; Tator and Fehlings, 1991; Hall, 1993; Young, 1993). It has been difficult to isolate the contribution of individual factors and to estimate their importance in producing the overall long-term histopathological and functional consequences of SCI. The recent development of new pharmacological tools, drugs of high selectivity and potency, has provided the opportunity to examine experimentally the role of various mechanisms in secondary injury. To accomplish this purpose, it is necessary to obtain data from dose-response studies with highly specific compounds.

The existence of post-traumatic local ischemia after $\mathrm{SCI}$, coupled with evidence that excitatory amino acids (EAA) contribute to ischemic brain damage (Simon et al., 1984), provided the rationale for initial studies on the effects of EAA antagonists on outcome after SCI (Faden and Simon, 1988). Selective antagonists of the NMDA-preferring subclass of EAA ionotropic receptors were shown to reduce the functional deficits produced by a standardized traumatic SCI (Faden and Simon, 1988; Faden et al., 1988b, 1990; Gomez-Pinella et al., 1989). Both systemic and intrathecal routes of administration were effective. However, in traumatic SCI models, little (Gomez-Pinella et al., 1989) or no (Faden et al., 1988b) sparing of tissue at the lesion site was found, raising questions on the mechanism(s) through which functional deficits were reduced.

In additional studies on the role of EAA receptors in $\mathrm{SCI}$, we found that kynurenic acid (KYNA), a nonspecific antagonist 
that inhibits both NMDA and non-NMDA ionotropic receptors (Birch et al., 1988; Danysz et al., 1989), was effective in reducing the consequences of injury under conditions in which potent NMDA receptor antagonists were ineffective (Wrathall et al., 1992a). We hypothesized that non-NMDA ionotropic receptors may be important in secondary injury. The first support for this hypothesis was obtained when we found that NBQX, a highly selective antagonist of AMPA and kainate receptors (Sheardown et al., 1990), administered beginning 5 min prior to SCI, significantly reduced the hindlimb deficits that result from a standardized injury (Wrathall et al., 1992b). A single dose of NBQX was used, the maximum that could be administered under the conditions of the experiment, leaving open the question of the specificity of the observed effects.

We have now performed a dose-response study in which varying concentrations of NBQX were focally administered into the injury site beginning at $15 \mathrm{~min}$ after SCI. We determined the effects on functional deficits over time after SCI and on quantitative histopathology, and serotonin immunoreactivity, at 4 weeks after injury. The resulting data were also used in regression analyses to examine the relationship between alterations in histopathology and functional impairment in NBQXtreated rats. The results demonstrate that NBQX reduces the functional defects resulting from SCI in a dose-dependent manner and suggests that it does so by significantly reducing secondary loss of spinal cord tissue.

\section{Material and Methods}

Spinal cord injury. Female Sprague-Dawley rats (200-250 gm) were anesthetized with chloral hydrate $(360 \mathrm{mg} / \mathrm{kg}$, i.p.), and a laminectomy was performed at the T8 vertebral level to expose a 2.8 -mm-diameter circle of dura. The animal was stabilized with angled Allis clamps on the $T 7$ and $T 9$ spinous processes, the impounder tip of a weight-drop device lowered onto the dura, and a $10 \mathrm{gm}$ weight dropped $2.5 \mathrm{~cm}$ onto the impounder to produce a spinal cord contusion, as previously described (Wrathall et al., 1985). This model of contusive injury has been characterized in terms of biomechanics (Panjabi and Wrathall, 1988), functional deficits produced (Gale et al., 1985; Wrathall et al., 1985), somatosensory evoked potentials (Raines et al., 1988), effects on the blood-spinal cord barrier (Noble and Wrathall, 1989b), and quantitative histopathology (Noble and Wrathall, 1985, 1989a).

After contusive injury, manual expression of bladders was performed twice daily until a reflex bladder was established, usually in the second week postoperatively. Postoperative care also included housing the rats in pairs to reduce isolation-induced stress, maintaining ambient temperature at $22-25^{\circ} \mathrm{C}$, and using highly absorbent bedding, as previously described (Wrathall et al., 1985), except that no prophylactic antibiotics were given.

$N B Q X$ administration. NBQX (sodium salt), a highly selective antagonist of AMPA/kainate receptors (Sheardown et al., 1990), was a gift of Novo Nordisk A/S (Malov, Denmark). NBQX was dissolved in deionized water (final pH 7.4) at a concentration of $3 \mathrm{mg} / \mathrm{ml}$ and diluted with vehicle as required. Vehicle (VEH) control animals received saline solution of similar osmolality and $\mathrm{pH}$. Solutions were sterilized through $0.22 \mu \mathrm{m}$ filters (Gelman Sciences, Ann Arbor, MI) and microinjected into the injury site beginning at $15 \mathrm{~min}$ after contusive injury. A total volume of $1.68 \mu \mathrm{l}$ of solution was injected into the center of the injury site over a period of $8 \mathrm{~min}$, through a sterotaxically placed 33 gauge needle, as previously described (Hoovler and Wrathall, 1991; Wrathall et al., 1992b). The dosages of NBQX used were $1.5,5$, and $15 \mathrm{nmol}$, the latter representing the maximum that could be administered in this volume due to the limited solubility of the drug. The volume of solution and the slow injection paradigm were used to maximize the focal delivery to the injury site, based on preliminary dye injection experiments (Wrathall et al., 1992b).

Experimental protocol. The experiment was performed according to a randomized block design. Experimental group sizes were chosen on the basis of power analyses of outcome measure data from injury doseresponse studies using this model of SCI (Gale et al., 1985; Noble and
Wrathall, 1985; Wrathall et al., 1985). Based on these analyses, with 12 rats per group there is an $80 \%$ probability of detecting an effect equal to or greater than $34 \%$ in inclined plane score, $25 \%$ in the combined behavioral score, and $15 \%$ in white matter area at the epicenter (see below for description of these outcome measures). On each surgery day, four rats were subjected to contusive injury and randomly assigned to receive one of the three NBQX solutions (doses of $1.5,5$, or $15 \mathrm{nmol}$ ) or the VEH alone. The groups of NBQX-treated rats and VEH controls ( $n=12$ per group) were behaviorally tested at $1 \mathrm{~d}$ and weekly thereafter through 1 month after injury. They were then reanesthetized and spinal cord tissue fixed by perfusion for histopathological analyses, as described below.

Behavioral tests of functional deficits. Tests of functional deficits were performed by individuals blind to the treatment groups. At each time point a battery of tests of hindlimb refiexes as well as coordinated use of hindlimbs were used, as previously described (Gale et al., 1985; Kerasidis et al., 1987). The reflexes tested included toespread, placing, withdrawal in response to extension, pressure or brief pain, righting, and the reflex to lick the toes in response to heat. Coordinated motor activity assessed included open-field locomotion, swimming, and ability to maintain position on an incline plane. Results in individual tests were examined separately and, in addition, overall hindlimb impairment was estimated with a combined behavioral score (CBS) that ranges from 0 in a normal rat to 100 in a rat with no evidence of hindlimb function. The CBS was developed on the basis of initial injury doseresponse experiments (Gale et al., 1985). It exhibits a normal distribution, as formally tested with the Wilk-Shapiro procedure (Shapiro and Wilk, 1965), and was designed as a parametric statistic to provide a continuous measure of overall hindlimb deficits that is correlated to injury severity. It has greater statistical power than any of its component behavioral tests (Gale et al., 1985) and is significantly correlated with both degree of initial mechanical injury (Panjabi and Wrathall, 1988) and chronic histopathology (Noble and Wrathall, 1985, 1989a). Although not an actual percentage measure, within the context of this injury model the CBS is used to estimate the "percentage deficil" after SCI.

Histopathology. After the 4 week behavioral testing, animals were anesthetized with chloral hydrate and perfused intracardially with saline followed by $4 \%$ paraformaldehyde in phosphate-buffered saline $(\mathrm{pH}$ 7.4). Spinal cord tissue was removed from the vertebral canal and a 1.5 $\mathrm{cm}$ segment centered on the injury site left in fixative for an additional hour, then equilibrated with increasing concentrations of sucrose solutions $(10-20 \%)$ and frozen with dry ice-isopentane $\left(-50^{\circ} \mathrm{C}\right)$. Ten spinal cords in each group were sectioned for morphometric and immunocytochemical analyses. The average CBS in each group was statistically indistinguishable from that of the relevant larger group $(n-12)$ for which behavioral data are reported. Serial $20 \mu \mathrm{m}$ cross sections were cut with a Jung Frigicut $2800 \mathrm{E}$ cryostat, mounted with five sections (100 $\mu \mathrm{m}$ of tissue) per slide, on slides that were coated with 3-aminopropyltriethoxysilane (Koo et al., 1988). All morphological analyses were done with tissue identified only by animal number; the evaluator was blind to the treatment group until after the primary data was collected.

For morphometry, every 10th slide was stained with luxol blue/hematoxylin and eosin and projected, and areas of gray matter, myelinated white matter, lesion cells (largely macrophages), and cavities were traced as previously described (Noble and Wrathall, 1985). The tracings were digitized and areas of each tissue component calculated with a Zeiss IBAS image analysis system, through which three-dimensional reconstructions of the lesions were also generated.

For immunocytochemistry, rabbit antibody to serotonin (5HT) conjugated to bovine serum albumin (BSA) with paraformaldehyde was purchased from Incstar, Inc. (Minneapolis, MN, cat. \#20080). The antibody was purified with the aid of a BSA-agarose (Sigma, St. Louis, $\mathrm{MO}$, cat. \#A-3790) column, to preclude nonspecific binding to BSA, and used at a dilution of 1:2000, as a marker for descending serotonergic innervation from the brainstem (Skagerberg and Bjorklund, 1985; Tork, 1990). Spinal cord sections were selected that represented $5 \mathrm{~mm}$ caudal to the lesion epicenter. All of the selected sections were processed for immunocytochemistry together, along with sections through the thoracic cord of uninjured controls, using the same solutions to allow comparison of the relative staining for 5HT. Using a Zeiss IBAS image analysis system, fields of view containing the left or right (1) superficial laminae of the dorsal horn, (2) intermediolateral horn, (3) ventral horn, and (4) the central canal-ventral commissure area were analyzed sep- 


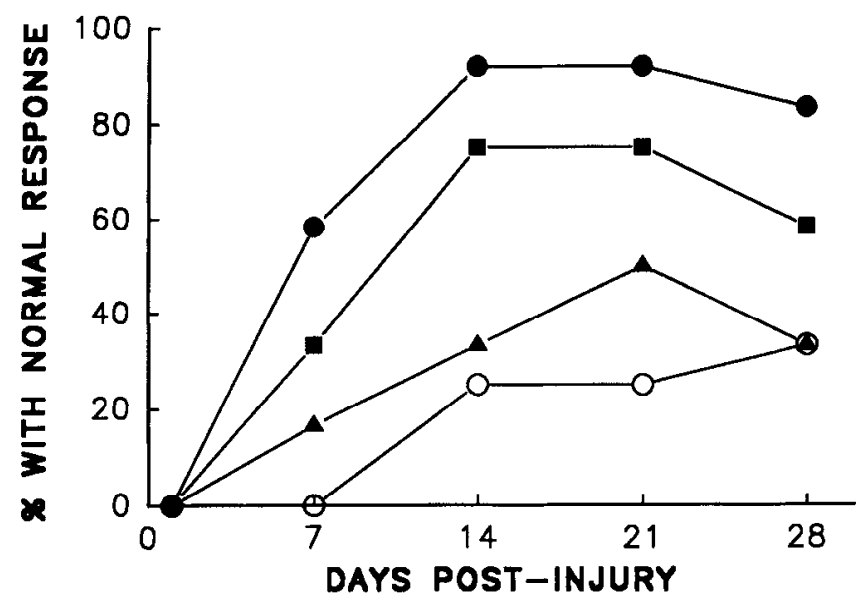

Figure 1. Effect of NBQX on recovery of the reflex to withdraw the hindlimb in response to pressure applied to the toe pads (pressure withdrawal reflex). Data points represent the percentage of rats in each group ( $n=12$ per group) that exhibit a normal reflex for rats receiving vehicle alone $(0)$ or $1.5(\Lambda), 5.0(\square)$, or $15(\Theta) \mathrm{nmol}$ of NBQX.

arately to determine the total areas (pixels) of stained immunoreactive terminals, using the same processing parameters for all samples. The data were combined to estimate total immunoreactivity $\left(\mu \mathrm{m}^{2}\right)$ for each area and for each spinal cord cross section.

Statistical analyses. As both CBS and inclined plane data represent parametric data and were repeatedly measured after injury, the effects of treatments were compared statistically using repeated-measures ANOVA, followed by Tukey's test for differences at individual time points. The appropriateness of the model, initially recommended by Dr. D. Mundt, Division of Biostatistics and Epidemiology, Georgetown University, and used in previous studies (Wrathall et al., 1992a,b), was tested with each individual set of data using the SAS statistical software. Nonparametric data (i.e., motor scores) were compared with the Wilcoxon test, as well as Bartholomew's test for trend of proportions. For comparison of areas of spared tissue at different levels of the spinal cord rostral and caudal to the epicenter, and 5HT-immunoreactive terminal areas caudal to the SCI in treated and VEH control groups, one-way ANOVA was used. For linear regression analyses, Pearson's correlation coefficient was calculated for parametric data and Spearman's coefficient for nonparametric data. In all cases, confidence limits were set at $95 \%$. Use of the term "significant" in the text indicates that statistical testing was performed and $p<0.05$.

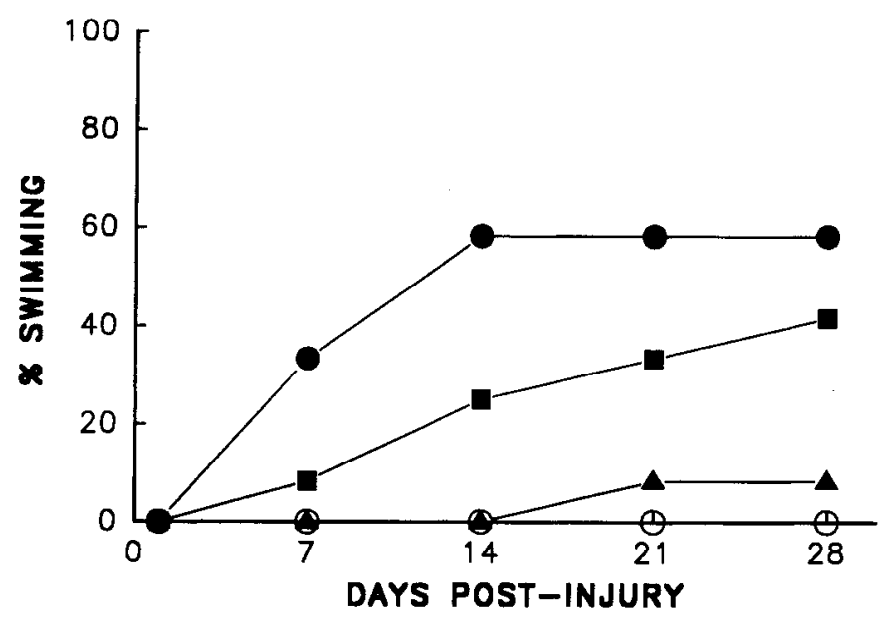

Figure 2. Effect of NBQX on recovery of swimming performance over time after injury. Data points represent the percentage of rats in each group $(n=12)$ that use their hindlimbs in swimming. Groups received vehicle alone $(O)$ or $1.5(\triangle), 5.0(\square)$, or $15(\bullet) \mathrm{nmol}$ of NBQX.

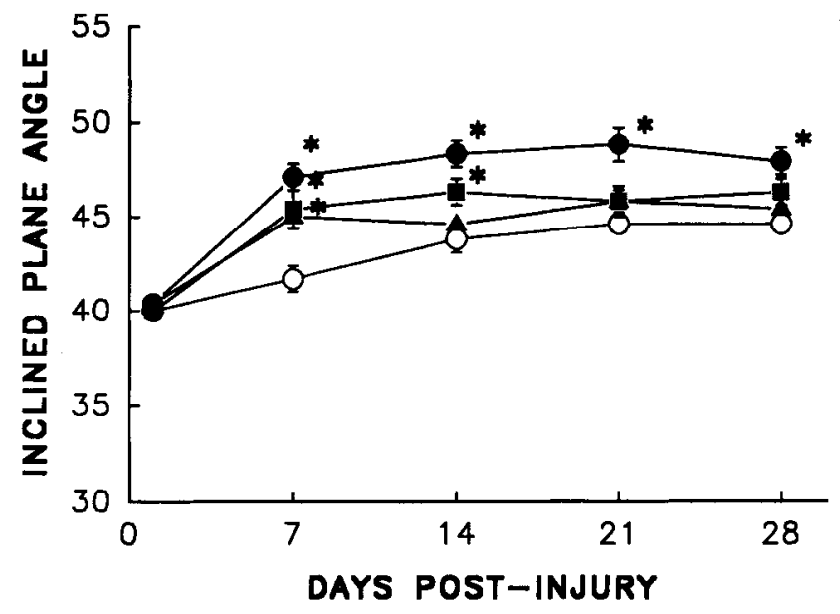

Figure 3. Effect of NBQX on incline plane performance over time after injury. Data points represent average \pm SEM maximum angle at which groups $(n=12)$ of rats can maintain position for $5 \mathrm{sec}$. Where error bars are not shown, the SEMs were smaller than the symbols. Groups treated with vehicle alone $(O)$ or $1.5(\Delta), 5.0(\square)$, or $15(\Theta) \mathrm{nmol}$ of NBQX. Data were analyzed with repeated-measures ANOVA, which showed an overall significant $(P<0.05)$ effect of treatment. Asterisks indicate that means are significantly different from the vehicle-treated control group at the specified times after SCI (Tukey's procedure).

\section{Results}

\section{Effects of $N B Q X$ on functional deficits after $S C I$}

As described previously in this model (Gale et al., 1985; Noble and Wrathall, 1989a), rats at $1 \mathrm{~d}$ after SCI demonstrated profound impairment of hindlimb function, including areflexia and inability to use their hindlimbs in coordinated motor functions such as locomotion. Over the next several weeks partial recovery of function was seen until a plateau was reached at 3-4 weeks representing the long-term, chronic deficits associated with this degree of SCI. Focal infusion of NBQX produced a dose-related effect in increasing the specd and extent of recovery of hindlimb reflexes after SCI, such as pressure withdrawal (Fig. 1) and others (data not shown). Recovery of coordinated motor function expressed in swimming (Fig. 2) and maintaining position on an inclined plane (Fig. 3) was enhanced. Recovery of locomotor function was also more rapid and occurred to a greater degree (Fig. 4), with both effects exhibiting dose dependence. Overall hindlimb functional deficits, as estimated by the Combined Behavioral Score (CBS), were reduced in a dose-related manner, with both the 15 and $5 \mathrm{nmol}$ groups demonstrating significantly better scores than VEH controls beginning 1 week after SCI and throughout the course of the experiment (Fig. 5).

After SCI, the normal control of micturation is lost and rats require manual expression of the bladder until a so-called reflex bladder is established, usually in the second week after SCI (Wrathall et al., 1985). In addition to the effects on hindlimb function, NBQX administration was associated with a significant and dose-related reduction in the time required to develop a reflex bladder (Fig. 6). All rats survived the full 4 week course of the experiment without evidence of any deleterious effects of treatment and no effect on weight gain after injury (data not shown).

\section{Effects of $N B Q X$ on the histopathological lesion produced by SCI}

Examination of spinal cord sections suggested a marked decrease in the extent of the lesions in many of the animals that 

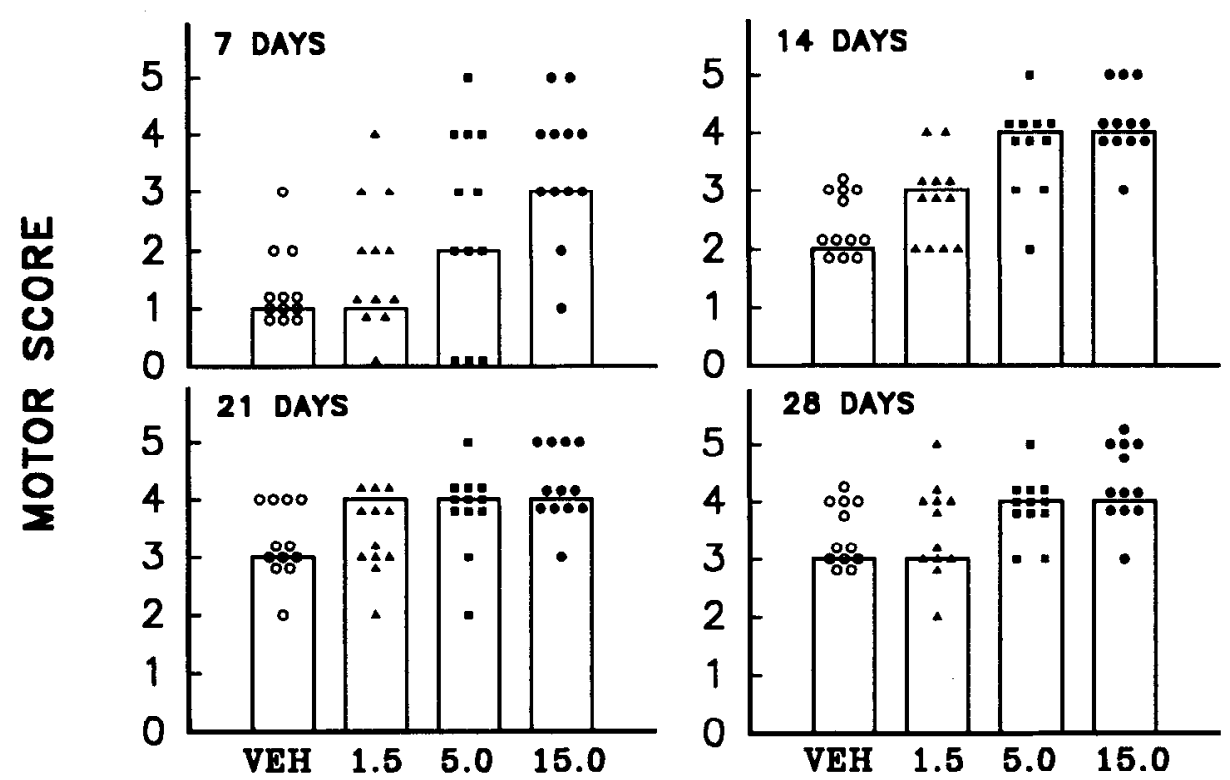

Figure 4. Effect of NBQX on speed and extent of recovery of locomotor function after SCI. Open-field locomotion was observed and graded on a 0-5 scale (the motor score, described in Wrathall et al., 1985) in which a grade of 3 or better indicates the ability to bear weight and use the hindlimbs for effective locomotion. Data points are individual scores for rats that reccived vehicle alone $(O)$ or $1.5(\Delta), 5.0(\square)$, or 15 (๑) $\mathrm{nmol}$ of NBQX; bars represent the modal score for the group. A significant $(P<0.05)$ treatment effect was present at each time point (Wilcoxon test). The extent of recovery as measured by the motor scores was significantly higher in the $5 \mathrm{nmol}$ group than controls at 7 and $14 \mathrm{~d}$, and for the 15 nmol group, scores were significantly higher at $7,14,21$, and 28 d postinjury. The speed of recovery of locomotion also demonstrated a significant doserelated effect as indicated by the proportion recovering locomotor ability (motor score of 3 or higher) at 7 and 14 d after SCI (Bartholomew's test for trend of proportions). received the highest dose of NBQX. As reported previously in this model (Noble and Wrathall, 1985, 1989a), the lesioned area of the cord exhibited an elongated ovoid form with maximal tissue loss, the lesion epicenter, at the site of the initial impact. Rostral and caudal to the epicenter the lesion tapered, with its most distal elements in the ventral portion of the dorsal funicular white matter. At the epicenter, the cross-sectional profile of the spinal cord was reduced compared to the normal thoracic cord, or cross sections of the injured cord rostral or caudal to the epicenter. The epicenters were characterized by a peripheral,

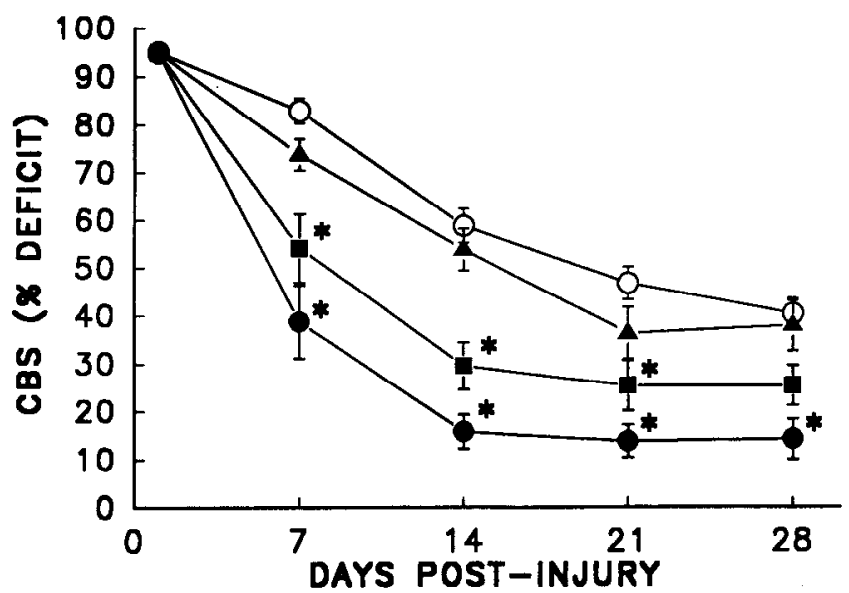

Figure 5. Effect of NBQX on overall hindlimb deficits over time after injury. Deficits are expressed as a combined behavioral score (CBS) that ranges from 0 in normal rats to 100 in rats with abnormal function in all of the tests. Data points represent the average of 12 rats per groun where groups received vehicle alone $(0)$ or $1.5(\Delta), 5.0(\square)$, or $15(\bullet)$ nmol of NBQX. Where no error bar is shown the SEM was smaller than the symbol. Data were analyzed with repeated-measures ANOVA, which showed an overall significant $(P<0.05)$ effect of treatment. Asterisks indicate that means are significantly different from the vehicletreated control group at the specified times after SCI (Tukey's procedure). often incomplete, rim of residual white matter, with the occasional presence of the most peripheral elements of gray matter. This residual spinal cord tissue surrounded the central lesion, consisting of cavities and a loose network of non-neuronal cells, mainly macrophages. Compared to VEH controls, in the group treated with $15 \mathrm{nmol}$ of NBQX there appeared to be more residual spinal cord tissue, mostly white matter, at the lesion epicenter (Fig. 7A,B). The cross-sectional profile frequently appeared larger and closer to the normal diameter of the spinal cord. Examination of sections rostral and caudal to the epicenter suggested that the length of the lesion was also less, especially in the group treated with $15 \mathrm{nmol}$ of NBQX (Fig. $7 C$ ).

These postulates were examined further using morphometric techniques. Determinations of gray matter area in sections of the epicenter and at specified distances rostral and caudal to it demonstrated a dose-dependent increase in residual gray matter

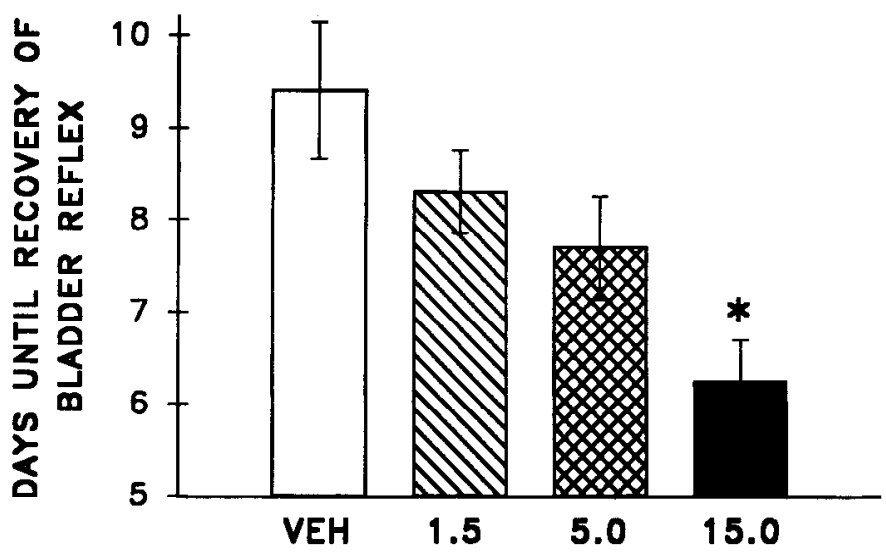

Figure 6. Effect of NBQX on the establishment of a reflex bladder after SCI. Bars represent the average $( \pm S E M)$ number of days until spontaneous bladder evacuation for groups $(n=12)$ treated with vehicle alone ( $\square$ ) or 1.5 (졍), 5.0 (国) or 15 (口) nmol of NBQX. Asterisk indicates significant difference $(P<0.05)$ from VEH control group (ANOVA). 
A<smiles>C1=CC=CCCCC=C1</smiles>

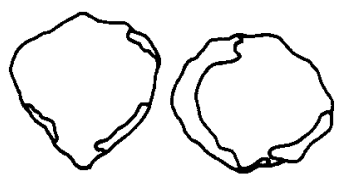<smiles>C1=CC2CCCCCC2CCCO1</smiles><smiles>C1=CCCCCCCCCCCCCC1</smiles><smiles>C1=CCCCCCCC1</smiles>

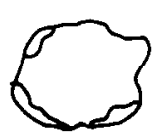<smiles>C1CC2CCCC(C1)OC2</smiles>

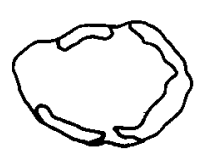<smiles>C1=CC2CCCCCCCC=CN(C=C1)C2</smiles>

$\mathbf{B}$
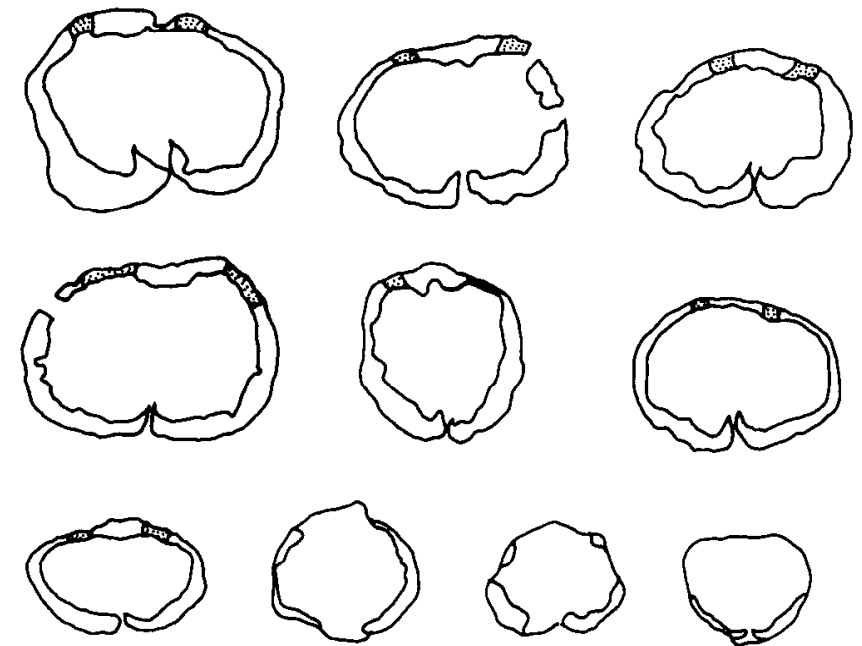
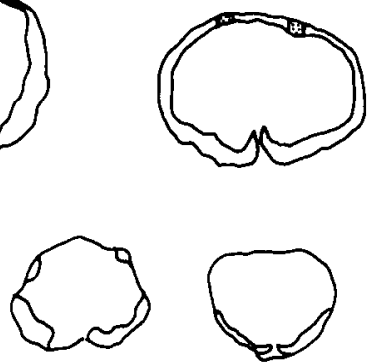

C
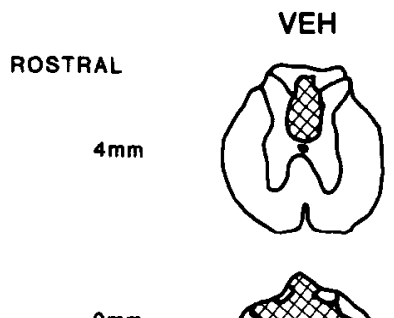

NBQX

$2 \mathrm{~mm}$
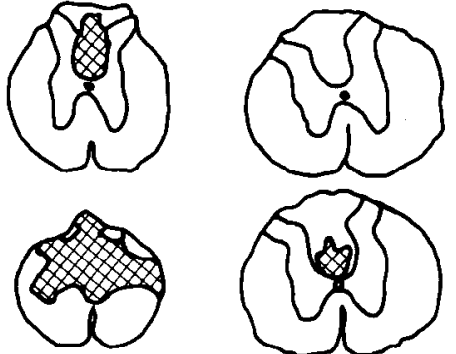

EPICENTER
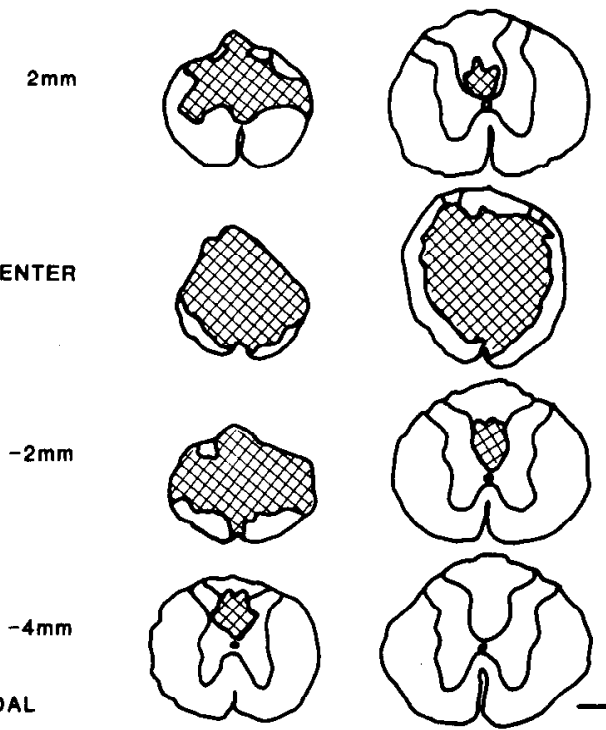

$-4 m m$

CAUDAL

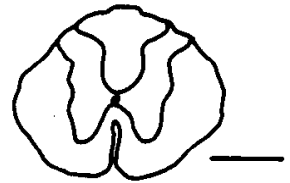

Figure 7. Effect of microinjected NBQX on residual spinal cord tissue at 4 weeks after injury. Tracing of sections through the lesion epicenters in groups of rats microinjected with VEH alone $(A)$, or $15 \mathrm{nmol}$ of NBQX $(B)$ at 15 min after SCI. Sections show an often incomplete rim of peripheral myelinated white matter, and in some cases peripheral portions of dorsal horn gray matter (stippled). The centers of the lesions contain cavities and a loose network of lesion cells (mostly macrophages), as previously described (Noble and Wrathall, 1985, 1989a), that are not distinguished in these tracings. $C$, Sections rostral and caudal to the epicenters from rats representative of those treated with vehicle alone (VEH) and those that received $15 \mathrm{nmol}$ of NBQX suggest a reduced rostrocaudal extent of the lesion (cross hatched) in the latter group. Scale bar, $1 \mathrm{~mm}$.

in sections adjacent to the epicenter (Fig. $8 A, C$ ). In sections at $2 \mathrm{~mm}$ rostral to the epicenter, the group that received $15 \mathrm{nmol}$ of NBQX averaged three times the area of residual gray matter; the $5 \mathrm{nmol}$ group, twice as much. Staining of adjacent sections with Nissl stains confirmed the presence of healthy-appearing neurons in this spared gray matter (data not shown). Although there was statistically significant sparing of gray matter at the epicenter in the group treated with $15 \mathrm{nmol}$ of NBQX, it was because of a complete absence of residual gray matter in VEH controls (Fig. 8C). A quantitatively much greater effect of NBQX was seen at 2-4 $\mathrm{mm}$ rostral or caudal to the epicenter, with a maximal effect at about $2 \mathrm{~mm}$.

Similar analyses of area of myelinated white matter indicated a dose-dependent increase at the epicenter as well as in sections rostral and caudal to it (Fig. $8 B$ ). In the group treated with the highest dose of NBQX (15 nmol), the average area of white matter at the epicenter was about double that in the VEH control group (Fig. 8D). The effect of NBQX in increasing residual white matter appeared quantitatively similar at the epicenter and in sections $1,2,3$, or $4 \mathrm{~mm}$ rostral or caudal to it.

Calculation of lesion lengths also showed a significant effect of NBQX (data not shown), with the group treated with the highest dose demonstrating a nearly $33 \%$ decrcasc in the length of the lesion. However, with respect to the average length of the lesion, the vehicle control and $1.5 \mathrm{nmol}$ groups were statistically similar, as were the 5 and $15 \mathrm{nmol}$ groups.
Antisera to serotonin $(5 \mathrm{HT})$ revealed reduced immunoreactivity caudal to the SCI as compared to that in normal spinal cords (data not shown). Quantitative analyses of immunoreactive terminals in sections $5 \mathrm{~mm}$ caudal to the epicenter at 1 month after SCI showed a dose-dependent effect of NBQX on overall terminal area, as well as $5 \mathrm{HT}$ terminals specifically in the dorsal horns, intermediolateral cell columns, in lamina $\mathrm{X}$ near the central canal, as well as in the ventral horns (Fig. 9). In the group treated with the maximal dose of NBQX, the total 5HT terminal area averaged more than twice that in the VEH control group.

\section{Correlation between tissue sparing and reduced functional deficits produced by $N B Q X$}

Linear regression analyses indicated significant correlations between sparing of tissue and reduction of functional deficits at 1 month after SCI. Degree of preservation of gray matter, white matter, and 5HT innervation below the injury site were each correlated to hindlimb locomotor function, as assessed by the motor score (Table 1). Further, the preservation of gray and white matter throughout the lesioned segments of the spinal cord, the area of myelinated white matter at the lesion epicenter, and the area of 5HT-immunoreactive terminals $5 \mathrm{~mm}$ caudal to the epicenter were significantly and strongly correlated to improvements in overall hindlimb function as estimated by the CBS (Table 1). 


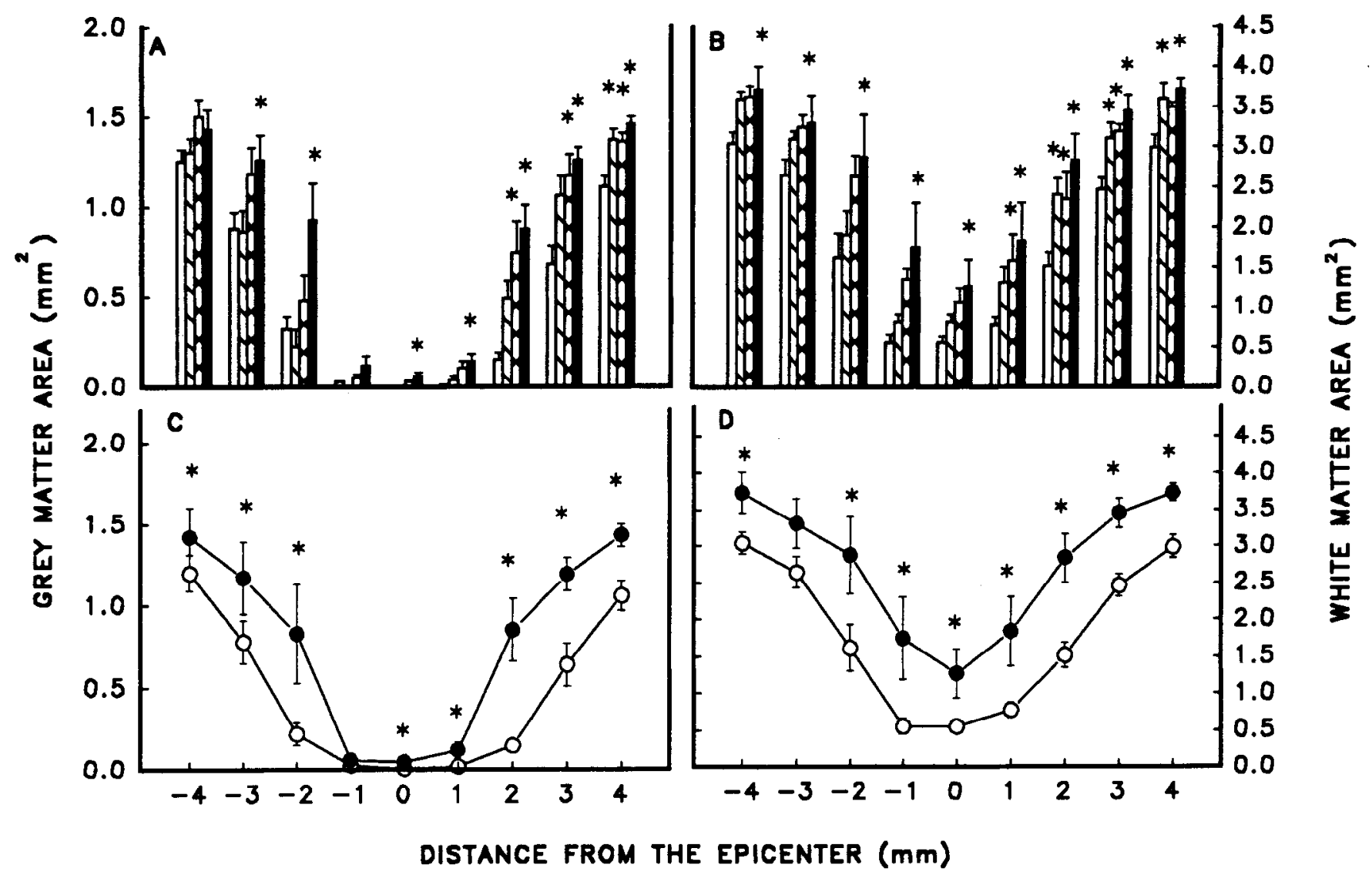

Figure 8. Effect of NBQX on morphometric measures of the spinal cord lesions at 1 month after injury. Sparing of gray matter $(A, C)$ and white matter $(B, D)$ in spinal cord sections caudal $(-1$ to $-4 \mathrm{~mm})$ and rostral $(1-4 \mathrm{~mm})$ to the injury epicenter. Data represent the average of sections

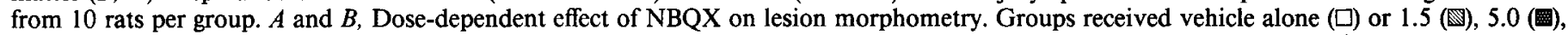
or $15(D)$ nmol of NBQX. $C$ and $D$, Effect of $15 \mathrm{nmol}$ of NBQX $(\odot)$, compared to vehicle $(O)$, on the rostrocaudal pattern of residual gray matter $(C)$ and white matter $(D)$. Where error bars are not shown, the SEMs were smaller than the symbols. Asterisks indicate a significant difference from the VEH control group $(P<0.05)$ when data were analyzed with one-way ANOVA. The significant differences in gray matter at the epicenter and $1 \mathrm{~mm}$ rostral level are due to its complete absence in the VEH group.

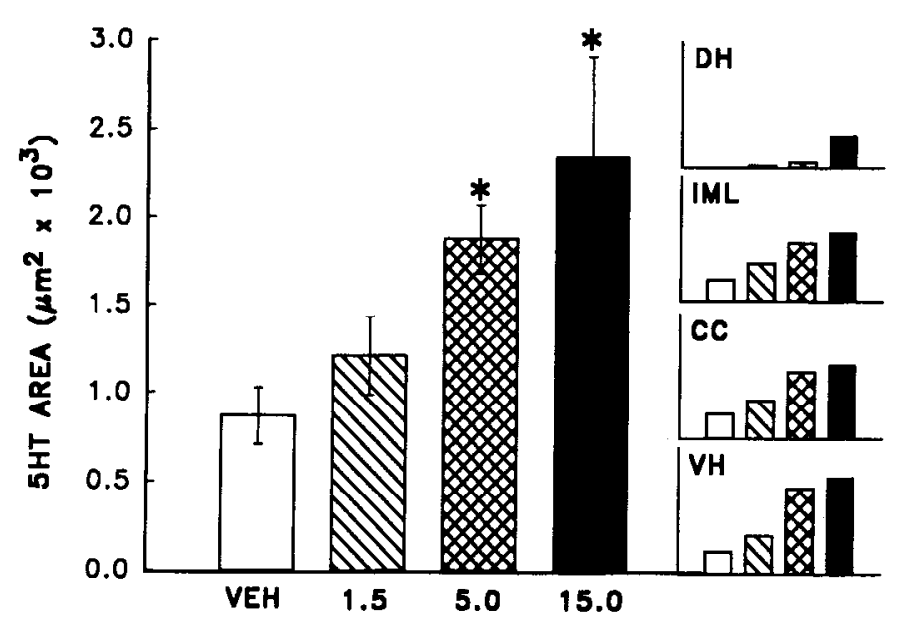

Figure 9. Effect of NBQX on spinal cord serotonin (5HT) immunoreactivity in sections $5 \mathrm{~mm}$ caudal to the injury site in groups $(n=7-$

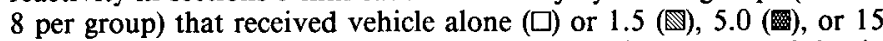
(D) nmol of NBQX. Data represent combined immunoreactivity in regions comprising the dorsal horns $(D H)$, intermediolateral horn $(I M L)$, central canal/ventral commissure $(C C)$, and ventral horns $(V H)$, as shown individually in insets. Asterisks indicate a significant difference from vehicle-treated control group ( $P<0.05$, one-way ANOVA).

\section{Discussion}

Our finding of a significant dose-related effect of NBQX, administered after a standardized contusive $\mathrm{SCI}$, in reducing tissue loss and functional deficits strongly implicates AMPA/kainate receptors in secondary injury processes that contribute to the

Table 1. Correlation between reduced functional deficits and tissue sparing

\begin{tabular}{llll} 
Relationship & $r / r_{\mathrm{s}}$ & $t / z$ & $P$ \\
\hline CBS vs injury site WM & 0.79 & 8.04 & $<0.005$ \\
CBS vs epicenter WM & 0.75 & 7.06 & $<0.005$ \\
CBS vs injury site GM & 0.70 & 5.88 & $<0.005$ \\
CBS vs 5HT at $-5 \mathrm{~mm}$ & 0.78 & 6.75 & $<0.005$ \\
MS vs injury site WM & 0.76 & 5.35 & $<0.005$ \\
MS vs epicenter WM & 0.75 & 5.84 & $<0.005$ \\
MS vs injury site GM & 0.69 & 5.23 & $<0.005$ \\
MS vs 5HT at $-5 \mathrm{~mm}$ & 0.72 & 4.85 & $<0.005$
\end{tabular}

Linear regression analyses were performed using the method of least squares to calculate Pearson's correlation coefficient $(r)$ for the parametric CBS data, and Spearman's rank order correlation to calculate $r_{\mathrm{s}}$ for the nonparametric motor score (MS) data. Injury site white matter (WM) and gray matter (GM) values were calculated as the sum of areas measured in individual cross sections of spinal cord at $2 \mathrm{~mm}$ intervals from $4 \mathrm{~mm}$ rostral to $4 \mathrm{~mm}$ caudal to the epicenter. Analyses were based on 29 rats for 5HT data (7-8 per experimental group), and 38 rats (910 per group) for the WM and GM data. 
overall deleterious effects of traumatic injury. Further, the effectiveness of focally applied NBQX, introduced into the injury site after SCI by stereotaxic microinjection, indicates that the relevant receptors are located on cells at or very near the injury site.

The study utilized a standardized model of contusive spinal cord injury in the rat that has been well characterized in terms of biomechanics (Panjabi and Wrathall, 1988), as well as behavioral (Gale et al., 1985; Wrathall et al., 1985; Kerasidis et al., 1987), neurophysiological (Raines et al., 1988), and histopathological (Noble and Wrathall, 1985, 1989a) outcome measures. The anesthetic used, chloral hydrate, is thought to be particularly useful in studies on CNS function (Waynforth and Flecknell, 1992), and at the dosage used $(360 \mathrm{mg} / \mathrm{kg}$, i.p.) produces a suitable level of anesthesia for surgery in Sprague-Dawley rats. We believe that the safety of this anesthetic, along with the absence of additional invasive procedures (e.g., arterial catheterization for physiological monitoring), contributed to the $100 \%$ survival rate for rats in this study. Further, chloral hydrate has no known direct effects on glutamate receptors.

Considerable evidence supports the hypothesis that the effects we observed are due to interaction of NBQX with local EAA receptors at or near the injury site. The microinjection paradigm used delivered a small volume of drug solution $(1.68 \mu 1)$ over a relatively long period of time $(8 \mathrm{~min})$ to largely restrict the infusion to the injury site, as determined by preliminary dyeinjection experiments (Wrathall et al., 1992b). Under these conditions, systemic effects on cardiorespiratory function or body temperature would be unlikely. However, in addition, body temperature was maintained both during surgery and postoperatively. It is therefore unlikely that the beneficial effects of NBQX that we observed were mediated through induction of hypothermia, as has been reported for MK-801 systemically administered to gerbils in an ischemic brain injury model (Buchan and Pulsinelli, 1990). However, only measurements of temperature within the spinal cord at the injury site could rule out the possibility of a local temperature effect by NBQX. In a separate experiment, we have monitored various physiological parameters (e.g., blood pressure, respiratory rate, blood gases, etc.) after NBQX was microinjected into the spinal cords of normal or SCI rats and found no significant alterations compared to VEH controls (Y. D. Teng and J. R. Wrathall, unpublished observations). Further, previous experiments using other antagonists of ionotropic receptors have also yielded evidence consistent with a role of local EAA receptors in contributing to the consequences of SCI (Faden et al., 1990; Wrathall et al., 1992a).

Several laboratories have shown that selective antagonists of the NMDA-preferring subclass of ionotropic receptors significantly reduce some of the consequences of experimental SCI. Faden and Simon (1988) initially found that dizocilpine (MK801 ), a noncompetitive NMDA antagonist, administered intravenously at $1 \mathrm{mg} / \mathrm{kg}, 15 \mathrm{~min}$ after a moderate $\mathrm{SCI}$, significantly reduced hindlimb functional impairments (locomotion, inclined plane) at 4 weeks after injury. Further studies confirmed the beneficial effects on locomotion and inclined plane score, and demonstrated a limited dose dependence of the effect on the former but not the latter (Faden et al., 1988b). The behavioral effects were not associated with significant tissue sparing at the epicenter, but 5HT immunoreactivity in the lumbar spinal cord was significantly higher in the treated group in one experiment. Using a model of SCI similar to that we used in this study,
Gomez-Pinella et al. (1989) demonstrated a significant sparing of neurons in gray matter adjacent to the lesion in rats treated with MK-801. Administration was initiated $1 \mathrm{hr}$ prior to SCI $(0.3 \mathrm{mg} / \mathrm{kg}$, i.p. $)$ and continued at $6-8 \mathrm{hr}$ after $\mathrm{SCI}$ with a subcutaneous infusion of $4.3 \mu \mathrm{g} / \mathrm{kg} / \mathrm{hr}$ for $14 \mathrm{~d}$. The neuroprotective effect was associated with improved function in some behavioral tests (locomotion, toespread reflex) but not others (inclined plane, withdrawal reflexes), and there was no significant effect on lesion length or volume.

The site of action of sytemically administered drugs is difficult to determine. Evidence for a role of local NMDA receptors in secondary injury was obtained by demonstrating the effectiveness of intrathecal administration of NMDA antagonists to the spinal cord near the injury site (Faden et al., 1990). Both the noncompetitive antagonist dextrophan and the competitive antagonist 3-(2-carboxypiperazin-4-yl)propyl-1-phosphonic acid (CPP) significantly improved locomotion at 4 weeks after SCI, with CPP also demonstrating a dose-dependent $(100 \mathrm{mg}$ better than $10 \mathrm{mg}$ ) effect on locomotion and 5HT levels caudal to the injury as well as a significant effect of the higher dose on inclined plane scores.

Evidence for the role of non-NMDA ionotropic receptors in SCI began to accumulate with a comparative study (Wrathall et al., 1992a) of the effects of intravenous MK-801, dextromethorphan, and kynurenic acid, a nonspecific antagonist of EAA receptors that can block both NMDA and non-NMDA receptors (Birch et al., 1988; Danysz et al., 1989). Under conditions in which the NMDA receptor antagonists were ineffective, we found that kynurenic acid significantly reduced functional deficits after SCI. It was also effective when administered intrathecally to the spinal cord or by direct microinjection into the injury site. With the later route of administration a significant dose-related effect was demonstrated, with significant improvement in a number of behavioral tests of hindlimb functional deficits. These results led to the hypothesis that nonNMDA ionotropic receptors may be important in secondary injury after spinal cord trauma (Wrathall et al., 1992a).

Initial support for this hypothesis came from studies in which we found that a $15 \mathrm{nmol}$ dose of NBQX microinjected into the injury site according to a split-dose protocol, in which half was administered $5 \mathrm{~min}$ prior to and the rest at $15 \mathrm{~min}$ after injury, significantly ameliorated the effects of injury on hindlimb function (Wrathall et al., 1992b). The results of the current study provide additional strong support for the hypothesis by demonstrating a dose-dependent reduction in both tissue loss and functional impairment when this highly selective antagonist of AMPA/kainate receptors (Sheardown et al., 1990) is administered after SCI.

AMPA receptors have been identified by electrophysiological studies of spinal cord neurons in vivo and in vitro (Davies and Watkins, 1983; Nelson et al., 1986; Headley and Grillner, 1990; Arencio et al., 1991; Salt and Herrling, 1991). These receptors are especially associated with monosynaptic responses to cutaneous myelinated afferents by neurons in both the dorsal and ventral horn. In addition, in the rat spinal cord, kainate receptors have been associated with neurons involved in the response to C-fiber afferents (Evans et al., 1987). However, in general, mammalian spinal neurons display a mixture of NMDA and nonNMDA receptor types.

The role of different types of receptors in EAA-mediated neurotoxicity has been under intensive investigation using tissue culture preparations of various types of neurons (Choi, 1992; 
Rothman, 1992). In cultures of cortical neurons, NMDA-preferring ionotropic receptors appear primarily responsible for rapidly triggered glutamate-induced cell death, but blockage of non-NMDA ionotropic receptors is also required to permit survival of neurons subjected to hypoxia and glucose deprivation for a prolonged period of time. Thus, NMDA receptors are postulated to be responsible for rapidly triggered excitotoxicity that is mediated by a rapid influx of $\mathrm{Ca}^{2+}$, and AMPA/kainate receptors for slowly triggered excitotoxicity in which the rate of $\mathrm{Ca}^{2+}$ influx is slower, and may involve routes other than receptor-gated channels (Choi, 1992). In either case, the increase in intracellular $\mathrm{Ca}^{2+}$ is believed to initiate destructive cascades of events (e.g., $\mathrm{Ca}^{2+}$-activated proteases) that lead to neuronal death. Our results indicate the importance of non-NMDA receptormediated neurotoxicity after SCI, perhaps that associated with the hypoxia and hypoglycemia engendered locally by the traumatic compromise of the blood supply (Tator and Fehlings, 1991).

The significant sparing of gray matter in rats treated with NBQX that we observed is consistent with reports of neuroprotection by NBQX against ischemic injury of cerebellar Purkinje cells (Balchen and Diemer, 1992), hippocampal CAl neurons (Diemer et al., 1992), and cerebral infarction induced by focal ischemia (Sheardown et al., 1990; Buchan et al., 1991b,c; Gill et al., 1992), or transient global ischemia (LePeillet et al., 1992; Nellgaard and Weiloch, 1992). However, ours appears to be the first report of NBQX-mediated neuroprotection after spinal cord trauma. Reduced neurotoxicity could in turn reduce other consequences of SCI, including edema, formation of oxygen-free radicals, and other molecules active in lipid peroxidation reactions (Hall, 1993), that may indirectly exacerbate the effects of the initial trauma on white matter.

NBQX may also act at astrocytic glutamate receptors to modify their response to injury. Although neurons responsive to glutamate typically possess a variety of receptors, astrocytic glutamate receptors appear restricted to non-NMDA types (Usowicz et al., 1990). In addition, recent studies on glutamate receptors in white matter, as represented by the optic nerve, suggest that a small population of $\mathrm{O} 2 \mathrm{~A}$ glial precursors exist in adult white matter, and that they also appear to have functional non-NMDA ionotropic receptors (Fulton et al., 1992; Jensen and Chiu, 1993). Thus, the effects of focally applied NBQX on spinal cord injury may be mediated through receptors on both neurons and glia and/or glial precursor cells.

Little is known about the role of glial receptors in traumatic injury. For example, astrocyte cultures are resistant to levels of glutamate that are toxic to neurons (Chan et al., 1990). Oligodendrocyte cultures are sensitive to glutamate toxicity, but are not protected by the presence of either NMDA or non-NMDA receptor antagonists (Oka et al., 1993), although NBQX has not yet been tested. However, the presence of glia in neuronal cultures modifies and reduces the extent of neurotoxicity mediated by glutamate (Rosenberg and Aizenman, 1989). Further, activation of glial glutamate receptors sets up a wave of elevation of intracellular free $\mathrm{Ca}^{2+}$ (Cornell-Bell et al., 1990), indicating a potential signaling mechanism through astrocytic networks. Such mechanisms could be involved in indirect effects of NBQX on white matter and serotonergic fibers, as well as neuroprotection. Our speculative hypothesis is that the capacity of NBQX to act at glial as well as neuronal receptors could be the basis of its powerful effect in reducing both gray and white matter loss after SCI.
It is likely that the reduction in tissue loss after SCI in rats treated with NBQX is causally related to the reduction of functional deficits resulting from the standardized traumatic injury. In previous experiments with this model in which we varied the degree of impact on the spinal cord, we found that the intensity of impact, tissue loss, and degree of functional impairment were significantly correlated to one another (Noble and Wrathall, 1985, 1989a; Panjabi and Wrathall, 1988). We had not assessed 5HT in these studies, but other investigators, using a rat model of SCI similar to ours, have reported that loss of 5HT immunoreactivity caudal to the lesion was correlated to severity of experimental injury (Faden et al., 1988a). In the present study, we kept the degree of impact injury constant but both the tissue loss and functional consequences were significantly varied due to treatment with NBQX. The significant correlations between the measures of tissue sparing at the injury site, and apparent sparing of $5 \mathrm{HT}$ terminals caudal to the injury, with behavioral indicators of hindlimb function (motor score, CBS) are consistent with, although they do not prove, a causal relationship. There are alternative possibilities. For example, increased 5HT caudal to the lesion could be due to an effect of NBQX leading to enhanced sprouting of spared fibers rather than increased sparing of the fibers passing through the injury site. In either case, the significant correlation between functional improvement and increased 5HT immunoreactivity is considered particularly important because these terminals represent an important descending motor control pathway from the brainstem (Tork, 1990).

The effectiveness of NBQX in reducing the consequences of SCI has potential clinical ramifications. Although the present study was limited to focally administered NBQX, additional experiments indicate that a more clinically relevant systemic administration can also significantly reduce deficits after $\mathrm{SCl}$ (Wrathall, unpublished obscrvations). Determining its relative effectiveness for $\mathrm{SCI}$, compared to selective NMDA antagonists (Faden and Simon, 1988; Faden et al., 1988b, 1990; GomezPinella, 1989; Wrathall et al., 1992a) or nonspecific antagonists such as kynurenic acid (Wrathall et al., 1992a), will require further studies. Differences in the relative effectiveness of antagonists of different classes of glutamate receptors in vivo remain to be explained. Nevertheless, varying sensitivity to antagonists of NMDA and non-NMDA ionotropic receptors has been reported with different types of CNS injury. For example, selective NMDA antagonists appear to be powerful neuroprotectants after focal cerebral ischemia (e.g., Park et al., 1988), but can be ineffective in transient global ischemic injury (Buchan et al., 1991a). In the latter case, non-NMDA antagonists are protective (Buchan et al., 1991b; Nellgaard and Wieloch, 1992). In SCI, there is now evidence of beneficial effects with either NMDA or non-NMDA receptor antagonists. It will bc of considerable interest to determine whether a combination of both types of antagonists would be more effective than either alone, as has been reported for retinal ischemic injury (Mosinger et al., 1991) and neurons in vitro (Kakau et al., 1991). Thus, in addition to providing a tool to investigate mechanisms of secondary injury after spinal cord trauma, NBQX, or similar drugs, may offer additional therapeutic approaches to SCI.

\section{References}

Allen AR (1911) Surgery of experimental lesion of spinal cord equivalent to crush injury of fracture dislocation of spinal column. A preliminary study. JAMA 57:878-880. 
Allen AR (1914) Remarks on the histopathological changes in the spinal cord due to impact. An experimental study. J Nerv Ment Dis 41:141-147.

Arancio O, MacDermott AB (1991) Differential distribution of excitatory amino acid receptors on embryonic spinal cord neurons in culture. J Neurophysiol 65:899-913.

Balchen T, Diemer NH (1992) The AMPA antagonist, NBQX, protects against ischemia-induced loss of cerebellar Purkinje cells. Neuroreport 3:785-788.

Ballentine JD (1978a) Pathology of experimental spinal cord trauma. I. The necrotic lesion as a function of vascular injury. Lab Invest 39: 236-253.

Ballentine JD (1978b) Pathology of experimental spinal cord trauma. II. Ultrastructure of axons and myelin. Lab Invest 254-266.

Birch PJ, Grossman CJ, Hayes AG (1988) Kynurenate and FG9041 have both competitive and non-competitive antagonist actions at excitatory amino acid receptors. Eur J Pharmacol 151:313-315.

Blight AR (1991) Morphometric analysis of a model of spinal cord injury in guinea pigs, with behavioral evidence of delayed secondary pathology. J Neurol Sci 103:156-171.

Bracken MB, Shepard MJ, Collins WF, Holford TR, Young W, Baskin DS, Eisenber HM, Flamm E, Leo-Summers L, Maroon PH, Marshall LF, Perot PL, Piepmeier J, Sonntag VKH, Wagner FC, Wilberger JE, Winn HR (1990) A randomized controlled trial of methylprednisolone or naloxone in the treatment of acute spinal cord injury. $\mathrm{N}$ Engl J Med 322:1405-1411.

Bresnahan JC (1978) An electron microscopic analysis of axonal alterations following blunt contusion of the spinal cord of the Rhesus monkey (Macaca mulatta). J Neurol Sci 37:59-82

Buchan A, Pulsinelli WA (1990) Hypothermia but not the $N$-methylD-aspartate antagonist, MK-801, attenuates neuronal damage in gerbils subjected to transient global ischemia. J Neurosci 10:311-316.

Buchan A, Li H, Pulsinelli WA (1991a) The $N$-methyl-D-aspartate antagonist, $\mathrm{MK}-801$, fails to protect against neuronal damage caused by transient, severe forebrain ischemia in adult rats. J Neurosci 11 1049-1056.

Buchan AM, Li H, Cho S, Pulsinelli WA (1991b) Blockade of the AMPA receptor prevents CA1 hippocampal injury following severe but transient forebrain ischemia in adult rats. Neurosci Lett 132:255258.

Buchan AM, Xuc D, Huang ZG, Smith KH, Lesiuk H (1991c) Delayed AMPA receptor blockade reduces cerebral infarction induced by focal ischemia. Neuroreport 2:473-476.

Chan PH, Chu L, Chen S (1990) Effects of MK-801 on glutamateinduced swelling of astrocytes in primary cell culture. J Neurosci Res 25:87-93.

Choi DW (1992) Excitotoxic cell death. J Neurobiol 23:1261-1276.

Cornell-Bell AH, Finkbeiner SM, Cooper MS, Smith SJ (1990) Glutamate induces calcium waves in cultured astrocytes: long-range glial signaling. Science 247:470-473.

Danysz W, Fadda E, Wroblewski JT, Costa E (1989) Kynurenate and 2-amino-5-phosphovalerate interact with multiple binding sites of the $N$-methyl-D-aspartate-sensitive glutamate receptor domain. Neurosci Lett 96:340-344.

Davics J, Watkins JC (1983) Role of excitatory amino acid receptors in mono- and polysynaptic excitation in the cat spinal cord. Exp Brain Res 49:280-290.

Diemer NH, Jrgrnsen MB, Johansen FF, Sheardown M, Honore T (1992) Protection against ischemic hippocampal CA1 damage in the rat with a new non-NMDA antagonist, NBQX. Acta Neurol Scand $86: 45-49$.

Ducker T, Kindt G, Kempe L (1971) Pathological findings in acute experimental spinal cord trauma. J Neurosurg 35:700-708.

Evans RH, Evans SJ, Pook PC, Sunter DC (1987) A comparison of excitatory amino acid antagonists acting at primary afferent $\mathrm{C}$ fibers and motoneurons of the isolated spinal cord of the rat. $\mathrm{Br} \mathrm{J}$ Pharmacol 91:531-537.

Faden AL, Simon RP (1988) A potential role for excitotoxins in the pathophysiology of spinal cord injury. Ann Ncurol 23:623-626.

Faden AI, Gannon AL, Basbaum AI (1988a) Use of serotonin immunocytochemistry as a marker of injury severity after experimental spinal trauma in rats. Brain Res 450:94-100.

Faden AI, Lemke M, Simon RP, Noble LJ (1988b) $N$-methyl-D-aspartate antagonist MK801 improves outcome following traumatic spinal cord injury in rats: behavioral, anatomic, and neurochemical studies. J Neurotrauma 5:33-45.
Faden AI, Ellison JA, Noble LJ (1990) Effects of competitive and noncompetitive NMDA receptor antagonists in spinal cord injury. Eur J Pharmacol 175:165-174

Fulton BP, Burne JF, Raff MC (1992) Visualization of O-2A progenitor cells in developing and adult rat optic nerve by quisqualatestimulated cobalt uptake. J Neurosci 12:4816-4833.

Gale K, Kerasidis H, Wrathall JR (1985) Spinal cord contusion in the rat: behavioral analysis of functional neurological impairment. Exp Neurol 88:123-134.

Gill R, Nordholm L, Lodge D (1992) The neuroprotective actions of 2,3-dihydroxy-6-nitro-7-sulfamoyl-benzo(f)quinoxaline (NBQX) in a rat focal ischaemia model. Brain Res $580: 35-43$.

Gomez-Pinella F, Tram H, Cotman CW, Nieto-Sampedro M (1989) Neuroprotective effect of MK-801 and U-50488H after contusive spinal cord injury. Exp Neurol 104:118-124.

Hall ED (1993) The role of oxygen radicals in traumatic injury: clinical implications. J Emerg Med 11:31-36.

Hansebout RR, Kuchner EF, Romero-Sierra C (1975) Effect of hypothermia and of steroids upon recovery from experimental spinal cord compression injury. Surg Neurol 4:531-536.

Headley PM, Grillner S (1990) Excitatory amino acids and synaptic transmission: the evidence for a physiological function. Trends Pharmacol Sci 11:205-211.

Hoovler DW, Wrathall JR (1991) Implantation of neuronal suspensions into contusive injury sites in the adult rat spinal cord. Acta Neuropathol (Berl) 81:303-311.

Jensen AM, Chiu SY (1993) Expression of glutamate receptor genes in white matter: developing and adult rat optic nerve. J Neurosci 13: $1664-1675$.

Kaku DA, Goldberg MP, Choi DW (1991) Antagonism of non-NMDA receptors augments the neuroprotective effect of NMDA receptor blockade in cortical cultures subjected to prolonged deprivation of oxygen and glucose. Brain Res 554:344-347.

Kerasidis H, Wrathall JR, Gale K (1987) Behavioral assessment of functional deficits in rats with contusive spinal cord injury. J Neurosci Methods 20:167-189.

Koo EH, Hoffman PN, Price DL (1988) Levels of neurotransmitter and cytoskeletal protein mRNA's during nerve regeneration in sympathetic ganglia. Brain Res 449:361-363.

LePeillet E, Arvin B, Moncada C, Meldrum BS (1992) The nonNMDA antagonists, NBQX and GYKI 52466, protect against cortical and striatal cell loss following transient global ischaemia in the rat. Brain Res 571:115-120.

Mosinger JL, Price MT, Bai HY, Xiao H, Wozniak DF, Olney JW (1991) Blockade of both NMDA and non-NMDA receptors is required for optimal protection against ischemic neuronal degeneration in the in vivo adult mammalian retina. Exp Neurol 113:10-17.

Nellgaard B, Wieloch T (1992) Postischemic blockade of AMPA but not NMDA receptors mitigates neuronal damage in the rat brain following transient severe cerebral ischemia. J Cereb Blood Flow Metab 12:2-11.

Nelson PG, Pun RYK, Westbrook GL (1986) Synaptic excitation in cultures of mouse spinal cord neurons: receptor pharmacology and behavior of synaptic currents. J Physiol (Lond) 372:169-190.

Noble LJ, Wrathall JR (1985) Spinal cord contusion in the rat: morphometric analyses of alterations in the spinal cord. Exp Neurol 88: 135-140.

Noble LJ, Wrathall JR (1989a) Correlative analysis of lesion development and functional status after graded spinal cord contusive injuries in the rat. Exp Neurol 103:34-40.

Noble LJ, Wrathall JR (1989b) Distribution and time course of protein extravasation in the rat spinal cord after contusive injury. Brain Res 482:57-66.

Oka A, Belliveau MJ, Rosenberg PA, Volpe JJ (1993) Vulnerability of oligodendroglia to glutamate: pharmacology, mechanisms, and prevention. J Neurosci 13:1441-1453.

Panjabi M, Wrathall JR (1988) Biomechanical analysis of spinal cord injury and functional loss. Spine 13:1365-1370.

Park C, Nehls B, Graham D, Teasdale G, McCulloch J (1988) The glutamate antagonist MK-801 reduces focal ischemic brain damage in the rat. Ann Neurol 24:543-551.

Raines A, Dretchen KL, Marx K, Wrathall JR (1988) Spinal cord contusion in the rat: somatosensory evoked potentials as a function of graded injury. J Neurotrauma 5:151-160.

Rosenberg PA, Aizenman E (1989) Hundred-fold increase in neuronal 
vulnerability to glutamate toxicity in astrocyte-poor cultures of rat ccrebral cortcx. Neurosci Lett 103:162-168.

Rothman SM (1992) Excitotoxins: possible mechanisms of action. Ann NY Acad Sci 648:132-139.

Salt TE, Herrling PI (1991) Excitatory transmitter function in mammalian central pathways. In: Excitatory amino acids and synaptic function (Wheal $\mathrm{H}$, Thomson A, eds), pp 155-170. London: Academic.

Shapiro SS, Wilk MB (1965) An analysis of variance test of normality. Biometrika 52:591-612.

Sheardown MJ, Nielson EO, Hansen AJ, Jacobson P, Honore T (1990) 2,3-dihydroxy-6-nitro-7-sulfamoyl-benzo(F)quinoxaline: a neuroprotectant for cerebral ischemia. Science 247:571-574.

Simon RP, Swan JH, Griffiths T, Meldrum BS (1984) Blockade of $N$-methyl-D-aspartate receptors may protect against ischemic damage in the brain. Science 226:850-852.

Skagerberg G, Bjorklund A (1985) Topographic principles in the spinal projections of serotonergic and non-serotonergic brainstem neurons in the rat. Neuroscience 15:445-480.

Tator CH, Fehlings MG (1991) Review of the secondary injury theory of acute spinal cord trauma with emphasis on vascular mechanisms. J Neurosurg 75:15-26.

Tork I (1990) Anatomy of the serotonergic system. Ann NY Acad Sci 600:9-35.

Usowicz MM, Gallo V, Cull-Candy SG (1990) Multiple conductance channels in type- 2 cerebellar astrocytes activated by excitatory amino acids. Nature 339:380-383.

Waynforth HB, Flecknell PA (1992) Experimental and surgical technique in the rat, $\mathrm{p} 121$. New York: Academic.

Wrathall JR, Pettegrew R, Harvey F (1985) Spinal cord contusion in the rat: production of graded, reproducible injury groups. Exp Neurol 88:108-122.

Wrathall JR, Bouzoukis J, Choiniere D (1992a) Effect of kynurenate on functional deficits from traumatic spinal cord injury. Eur $J$ Pharmacol 218:273-281.

Wrathall JR, Teng YD, Choiniere D (1992b) Evidence that local nonNMDA receptors contribute to functional deficits in contusive spinal cord injury. Brain Res 586:140-143.

Young W (1993) Secondary injury mechanisms in acute spinal cord injury. J Emerg Med 11:13-22. 